\title{
FLORAÇÃO, FRUTIFICAÇÃO E SÍNDROMES DE DISPERSÃO DE UMA COMUNI- DADE DE FLORESTA DE BREJO NA REGIÃO DE CAMPINAS (SP) ${ }^{1}$
}

\author{
Andréa Pozetti Spina ${ }^{1,2}$ \\ Washington Marcondes Ferreira ${ }^{2}$ \\ Hermógenes de Freitas Leitão Filho ${ }^{2,3}$
}

Recebido em 30/08/00. Aceito em 25/07/01.

\begin{abstract}
RESUMO - ( Floração, frutificação e síndromes de dispersão de uma comunidade de floresta de brejo). Dados referentes as fenofases de floração e de frutificação, das espécies de uma floresta de brejo, foram analisados quanto à época de ocorrência e suas possíveis variações nos diferentes hábitos. Os dados foram obtidos mensalmente durante o levantamento florístico das plantas vasculares. Foram registrados: o hábito da espécie, a presença ou ausência de flores e/ou frutos, a cor e a textura dos frutos. Os dados de frutificação foram agrupados quanto à deiscência e textura dos frutos, e estes quando secos e deiscentes, foram analisados quanto à presença ou não de arilo ou arilóide, e de mecanismos explosivos de deiscência. Através desta análise as espécies foram classificadas quanto às síndromes de dispersão. Na comunidade a floração e a frutificação ocorreram durante o ano todo com um pico em junho, comum à maioria das espécies. Quando as espécies são agrupadas pelo hábito, são observadas diferenças quanto à época de ocorrência de seus picos de floração e de frutificação ao longo do ano. A síndrome de dispersão mais freqüente foi a zoocoria (75\% das espécies), seguida pela anemocoria (27\%) e pela autocoria (16\%). As espécies arborescentes e arbustivas apresentaram as maiores porcentagens de zoocoria $(75 \%$ e $57 \%$ respectivamente) enquanto que, $63 \%$ das espécies de lianas apresentaram anemocoria.
\end{abstract}

Palavras-chaves - Floresta de brejo, floração, frutificação, síndromes de dispersão

\begin{abstract}
Flowering, fruiting and dispersal syndromes of a wet forest community ), Flowering and fruiting phenophase data of species from a wet forest community were analyzed. The data were collected monthly during the floristic study. Habit, the presence or absence of flowers and/or fruits, and the color and texture of fruits were registered. Fruiting data were grouped in relation to dehiscence type and texture. When dry and dehiscent the fruits were discriminated by the presence of an aril or arillode or by the explosive dehiscence. By these analyses the species were classified according to their dispersal syndromes. In the community flowering and fruiting occurred during all the year with a peak of activity in June. When species are grouped by habit, differences in the peaks of flowering and fruiting during the year were observed. Zoochory was the most frequent syndrome (57\% of species), followed by anemochory $(27 \%)$ and autochory $(16 \%)$. For arborescents and shrubs, zoochory was the most frequent ( $75 \%$ and $57 \%$ of the species, respectively), and anemochory was most common in climbers species (63\%).
\end{abstract}

Key words - Wet forest, flowering, fruiting, dispersal syndromes

\footnotetext{
${ }^{1}$ Parte da Dissertação de Mestrado de Andréa Pozetti Spina.

${ }^{2}$ Departamento de Botânica, Instituto de Biologia, Universidade Estadual de Campinas, Caixa Postal 6109, 13081-970 Campinas, SP.

${ }^{3}$ In Memorian
} 


\section{Introdução}

Floração e frutificação são fases fenológicas dentro do ciclo de vida das plantas e, para estas, o ritmo sazonal destes eventos fenológicos pode ser crítico para a sobrevivência e reprodução (Rathcke \& Lacey, 1985). Em comunidades florestais, estes ritmos sazonais de floração e de frutificação podem mostrar padrões fenológicos característicos, os quais são relacionados com os fatores abióticos e bióticos desta comunidade. Os fatores abióticos podem limitar diretamente a época de floração afetando a habilidade de produzir flores, ou indiretamente, afetando os vetores de pólen; podem também limitar a época de amadurecimento dos frutos (Rathcke \& Lacey, 1985).

Os efeitos dos fatores bióticos sobre a época de floração e de frutificação, tais como a presença de polinizadores, dispersores e o parasitismo, são pouco estudados.

Estudos sobre os padrões fenológicos de comunidades florestais são escassos, principalmente aqueles que consideram outros hábitos além do arbóreo. Trabalhos realizados em floresta tropical como os de Frankie et al. (1974), Morellato et al. (1989) e Matthes (1980), relacionam o comportamento fenológico de espécies arborescentes com os fatores ambientais. Opler et al. (1980) estabelecem a mesma relação com espécies de arvoretas e arbustos, enquanto que Morellato \& Leitão Filho (1996) e Kim (1996), com lianas. Na região de Campinas o trabalho de Morellato (1991) se destaca por abordar a fenologia de espécies arbustivas, lianas e arborescentes de uma floresta mesófila semidecídua.

Trabalhos feitos nesta linha auxiliam muito na compreensão da dinâmica da comunidade florestal estudada, bem como sugerem as possíveis relações entre os fatores ambientais e as respostas biológicas dos indivíduos da comunidade. Pouco se sabe sobre as florestas de brejo; os dados se restringem a alguns estudos sobre sua composição florística e fitossociologia com base no hábito arbóreo (Torres et al., 1994; lva- nauskas et al., 1997 e Toniato et al., 1998). Mais escassos ainda são os trabalhos que apresentam dados sobre os eventos fenológicos dentro do ciclo de vida das espécies dessa formação vegetacional.

Neste trabalho foi analisado o comportamento fenológico de uma comunidade de floresta de brejo, através de dados referentes ao pico de floração e de frutificação das espécies desta comunidade, a fim de se verificar a época de ocorrência destes eventos fenológicos, bem como as suas possíveis variações, dentro dos diferentes hábitos das espécies desta comunidade florestal.

\section{Material e métodos}

Área de estudo - A área de estudo localizase no distrito de Barão Geraldo, município de

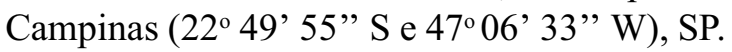
Esta é constituída por três fragmentos florestais que distam cerca de $500 \mathrm{~m}$ da Reserva Florestal de Santa Genebra e que, juntas, formavam antes um complexo vegetacional contínuo (Fig. 1). A região apresenta altitudes variando de 580 a 610m (Matthes, 1992), sendo que o primeiro e o segundo fragmentos situam-se em uma baixada e o relevo à sua volta é inclinado, enquanto que o terceiro fragmento apresenta um relevo plano. Os fragmentos estudados distam cerca de $100 \mathrm{~m}$ entre si, e caracterizam-se por apresentar solo predominantemente encharcado durante o ano todo, e um microrelevo irregular com as espécies distribuídas sobre "montículos de solo", rodeado por canaletas de drenagem da água proveniente do afloramento do lençol freático.

O clima da região é classificado, segundo Koeppen, como Cwa- tropical, com duas estações bem definidas, caracterizadas por um inverno seco e um verão quente e chuvoso (Oliveira et al., 1979). O regime pluviométrico de Campinas é caracterizado por um período com menor pluviosidade, que se inicia no outono (março a maio) e se estende até o inverno (ju- 


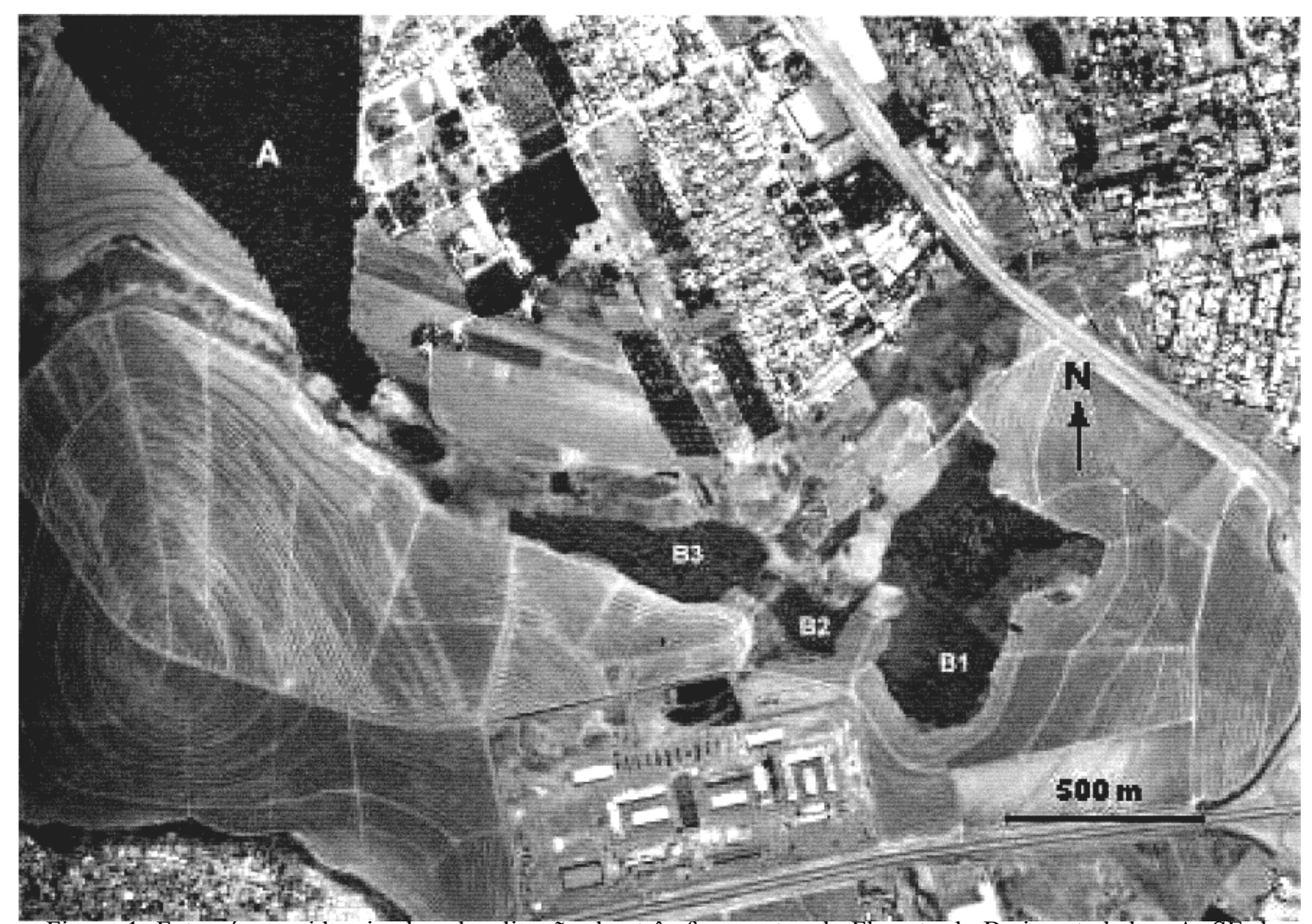

Figura 1. Foto aerea evidenciando a localização dos três fragmentos de Floresta de Brejo estudados. A. SE da Reserva Florestal de Santa Genebra; B1 - 3. Fragmentos de Floresta de Brejo estudados. Foto aérea cedida pela EMBRAPA - Monitoramento por Satélite.

nho a agosto), e por um período chuvoso que se inicia na primavera (setembro a novembro), atingindo um máximo de pluviosidade no verão (dezembro a fevereiro) (Mello et al., 1994).

O solo da área estudada pode ser classificado como hidromórfico e, quimicamente, este se apresenta muito ácido, rico em matéria orgânica, deficiente em cálcio, com baixos teores de fósforo e magnésio, e alta saturação de alumínio (Toniato et al., 1998).

Metodologia - As espécies foram identificadas com o auxílio da literatura e da comparação através de exemplares depositados no acervo do herbário UEC. Estas espécies foram classificadas segundo o sistema de Cronquist (1981) e os nomes dos autores foram abreviados segundo Brummitt \& Powell (1992). Os materiais testemunho foram depositados no Herbário da Universidade Estadual de Campinas (UEC).
Para o estudo dos picos de floração e de frutificação, foram utilizados os dados mensais obtidos durante o levantamento florístico das plantas vasculares, no período de abril de 1994 a março de 1995 (Spina, 1997).

Nas coletas dos materiais botânicos foram registrados os seguintes dados: o hábito (arborescente (árvores e palmeiras), arbustivo, subarbustivo, herbáceo, escandente (lianas)), a presença de flores e/ou frutos, a cor e a textura dos frutos. A classificação dos indivíduos nos diferentes hábitos foi baseada em Rizzini et al. (1983) e Font Quer (1979). Os dados de frutificação foram agrupados quanto à deiscência (deiscente ou indeiscente) e textura (carnoso e seco). Também foram agrupados quanto às síndromes de dispersão, com base na classificação de Pijl (1982), em três categorias: (1) anemocóricos - quando os diásporos apresentaram-se ala- 
dos, plumosos ou em forma de balão ou poeira; (2) zoocóricos - quando apresentaram atrativos e/ou fontes alimentares em seus diásporos, e também aqueles com estruturas adesivas (ganchos, cerdas, espinhos, etc.); (3) autocóricos quando não se encaixaram nas duas categorias anteriores, ficando nesta categoria as espécies barocóricas (dispersão por gravidade) e aquelas com dispersão explosiva.

Os dados fenológicos foram analisados em relação à comunidade como um todo, isto é, as espécies que se apresentaram em flor, mas não foram encontradas em fruto durante o período de coleta, não foram descartadas da análise da fenofase de floração, e este mesmo procedimento também foi adotado para os dados de frutificação.

\section{Resultados}

Floração - Foram coletadas 134 espécies em estudo florístico (Spina, 1997), e 64\% destas (86 espécies) foram observadas na fenofase de floração durante o período de coleta do material botânico (de abril 1994 a março 1995), sendo que este valor foi usado como unidade amostral na representação dos picos de floração da comunidade (Tabela 1, Fig. 2 A). As espécies da comunidade floresceram durante o ano todo, sendo que as maiores porcentagens (19 a 30\% das espécies) ocorreram durante os meses de junho (19\%), e de agosto a outubro (21 a 30\%) (Fig. 2 A).

Cerca de $81 \%$ das espécies floresceram durante uma única estação do ano (estação seca/ fria ou estação úmida/quente), e cerca de $18 \%$, ao longo das duas estações do ano (estação seca/ fria e estação úmida/quente) (Tab. 2). Dentro destes $18 \%$, estão representadas espécies de hábito arborescente, arbustivo e escandente (liana) (Tab. 2).

Quando analisamos os picos de floração das espécies de acordo com o seu hábito (Figs. 2 BF), podemos observar que o pico de floração apresentado em junho para a comunidade está associado à época de floração de cerca de $36 \%$ das espécies arbustivas (Fig. 2 B), por cerca de 14\% das espécies subarbustivas (Fig. 2 C), 13\% das espécies escandentes (lianas) (Fig. 2 D) e de $12 \%$ das espécies arborescentes (Fig. 2 E).

No entanto as espécies herbáceas não apresentaram espécies florescendo durante o mês de junho (Fig. 2 F). Em relação aos demais picos de floração que ocorreram ao longo do ano, foram observados que as espécies herbáceas apresentaram a maior porcentagem de floração durante a estação úmida e quente, cerca de $80 \%$, e a menor porcentagem de floração durante a estação seca e fria, apenas $20 \%$ (Tab. 2). Para as espécies subarbustivas também foi observado um maior porcentagem de floração durante a estação úmida ( $71 \%$ das espécies), apresentando um maior pico de floração em janeiro (43\%) e outros picos menores ao longo do ano todo (Tab. 2, Fig. 2 C). Entretanto, para as espécies arbustivas o maior pico de floração (38\% das espécies) ocorreu durante a estação seca (junho), sendo que no final desta estação e início da estação úmida ocorreu um aumento no número de espécies florescendo (19\%) e este atinge uma maior porcentagem (23\%) em dezembro (Fig. 2 B, Tab. 2).

Para as espécies arborescentes o maior pico de floração (37-39\% das espécies) ocorreu durante o final da estação seca e início da estação úmida (de setembro a outubro) (Fig. 2 E); enquanto que para as espécies de lianas o maior pico de floração (27-33\%) ocorreu durante a estação úmida (setembro a outubro) (Fig. 2 D). Outro aspecto que poderia ser relacionado com o pico de floração da comunidade seria a localização das espécies dentro da estratificação da floresta.

Na floresta de brejo estudada foram observados 3 estratos bem definidos: (1) o estrato arbóreo formado pelas espécies arborescentes e lianas, (2) o estrato arbustivo formado pelas espécies arbustivas e (3) o estrato herbáceo formado pelas espécies subarbustivas e herbáceas. Se analisarmos o pico de floração com base 







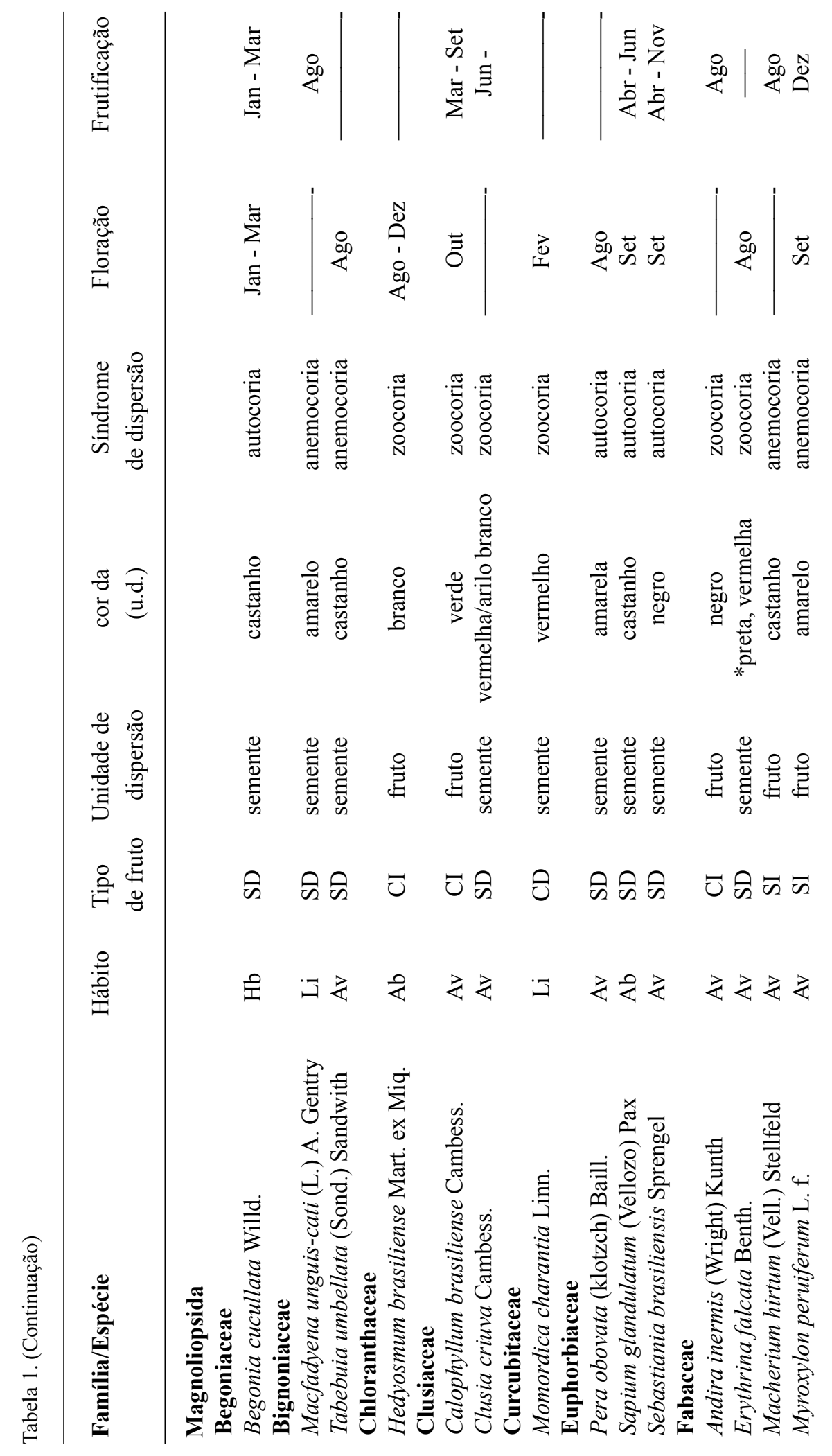




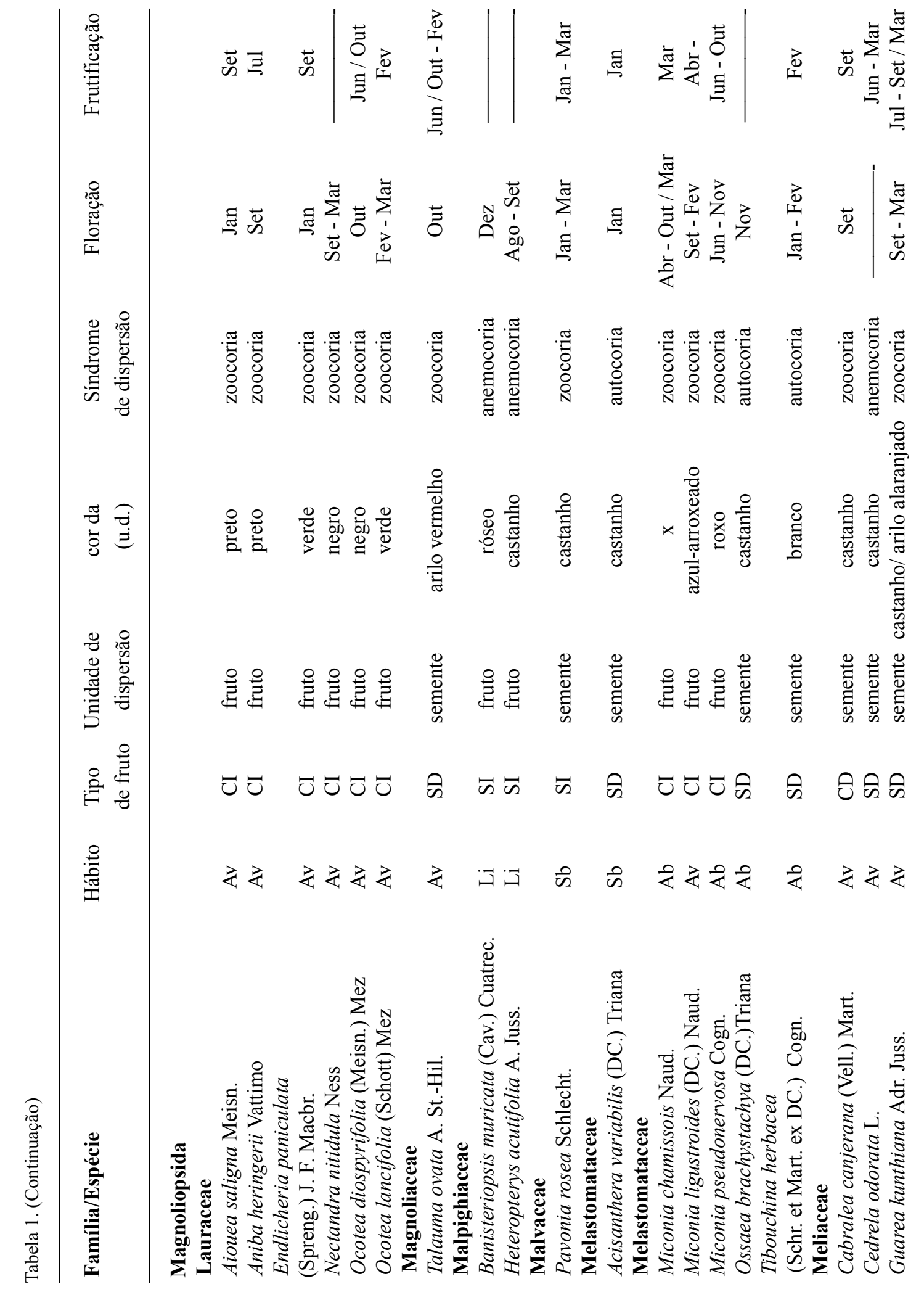




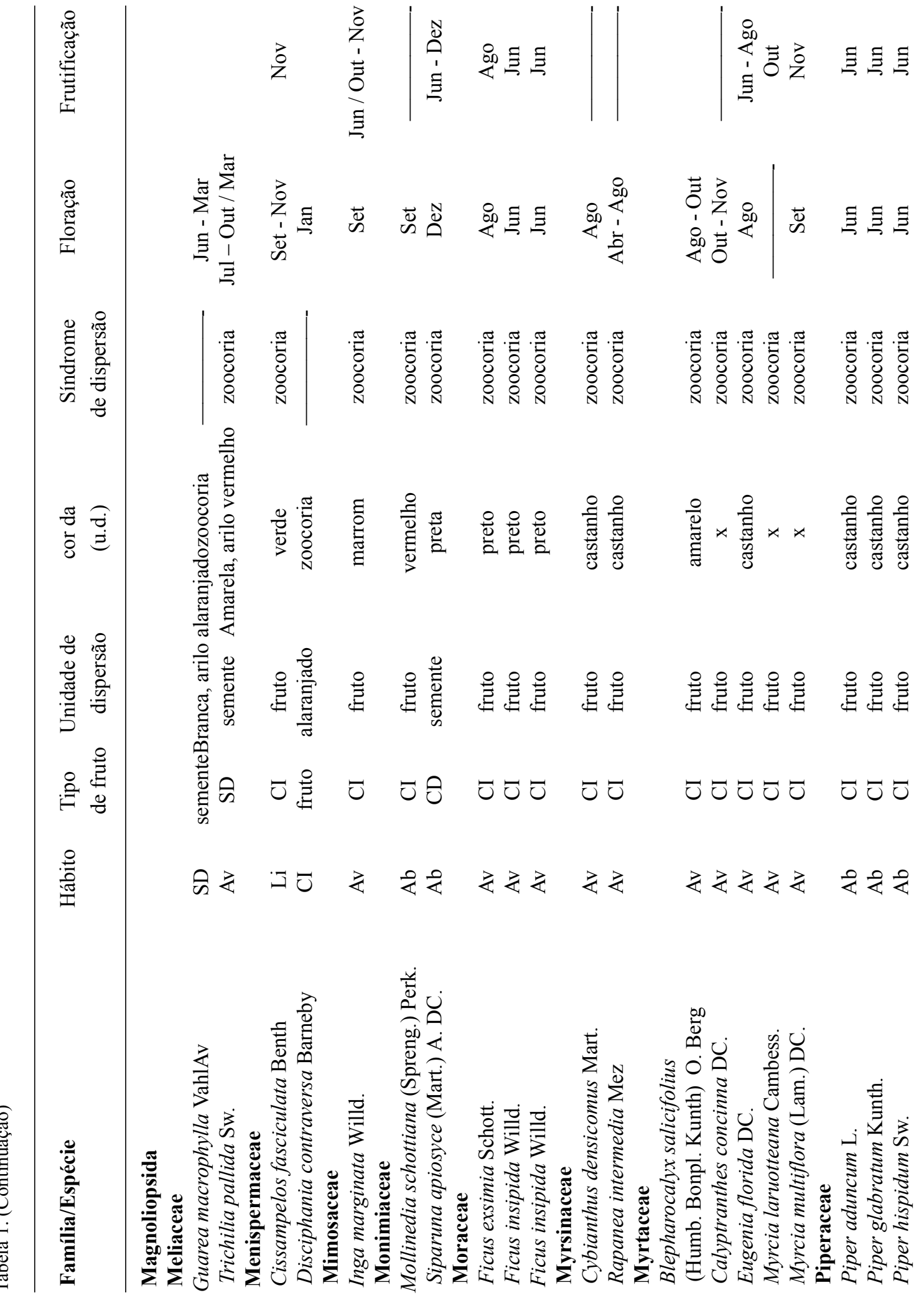




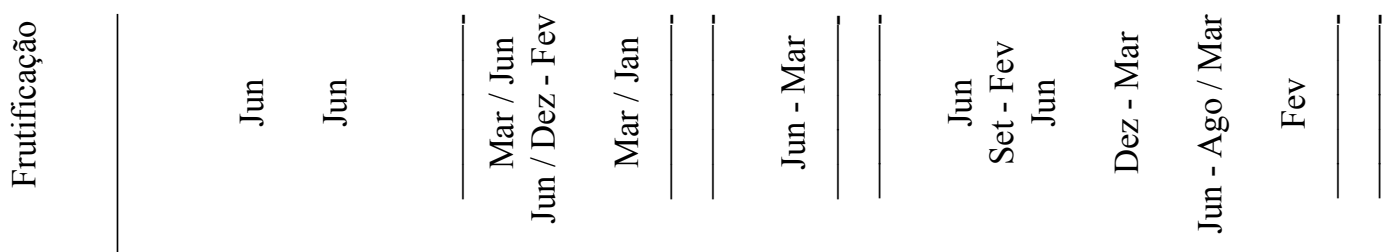

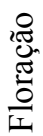

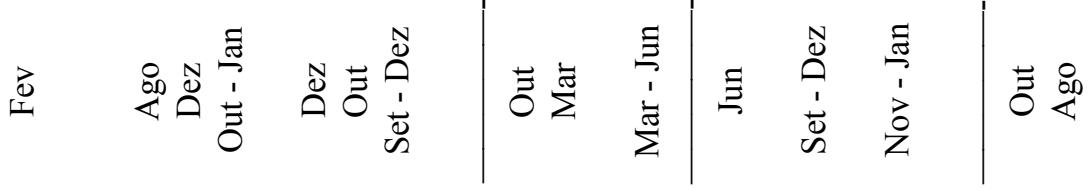

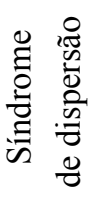

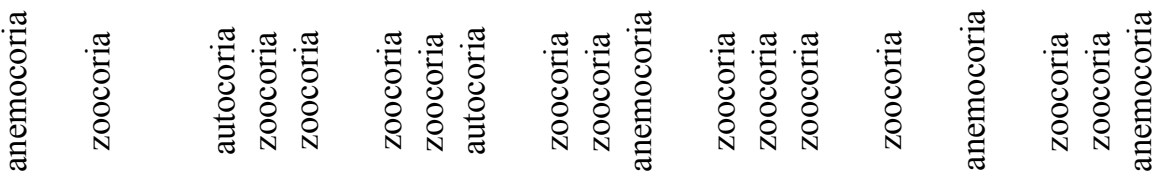

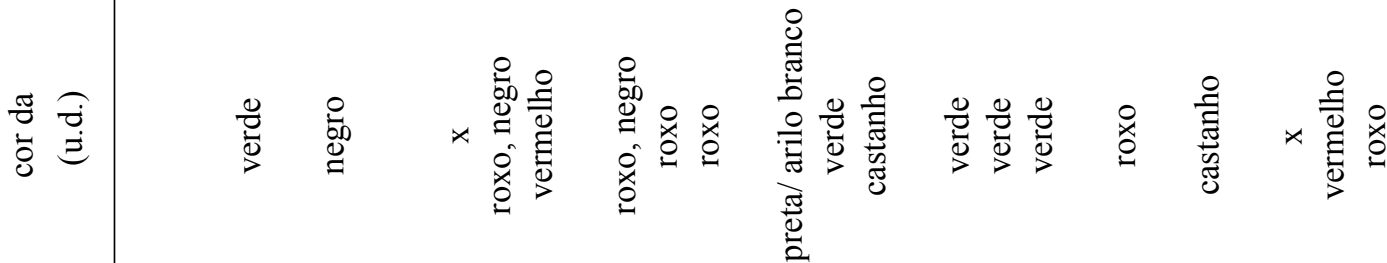

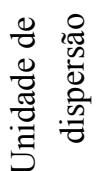

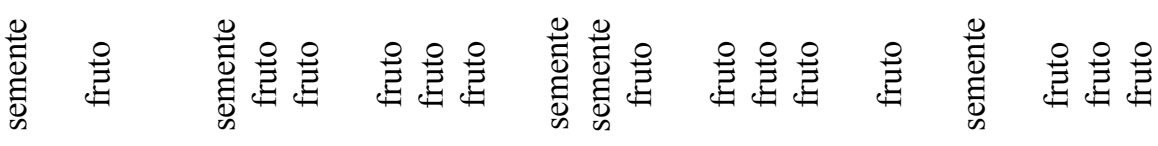

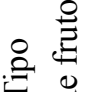



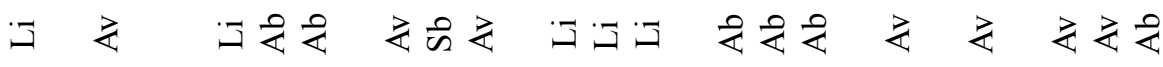

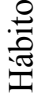

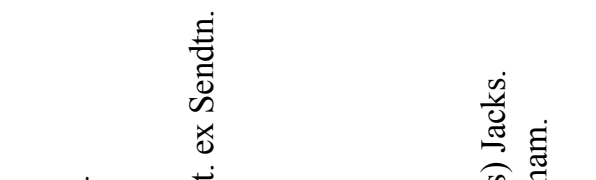

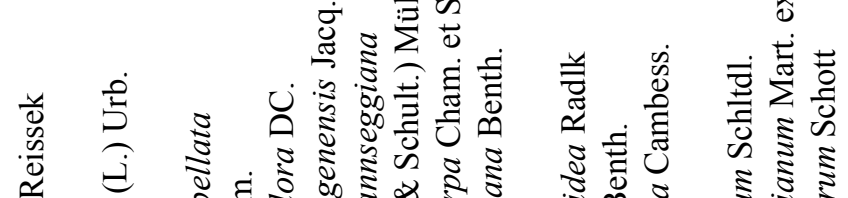




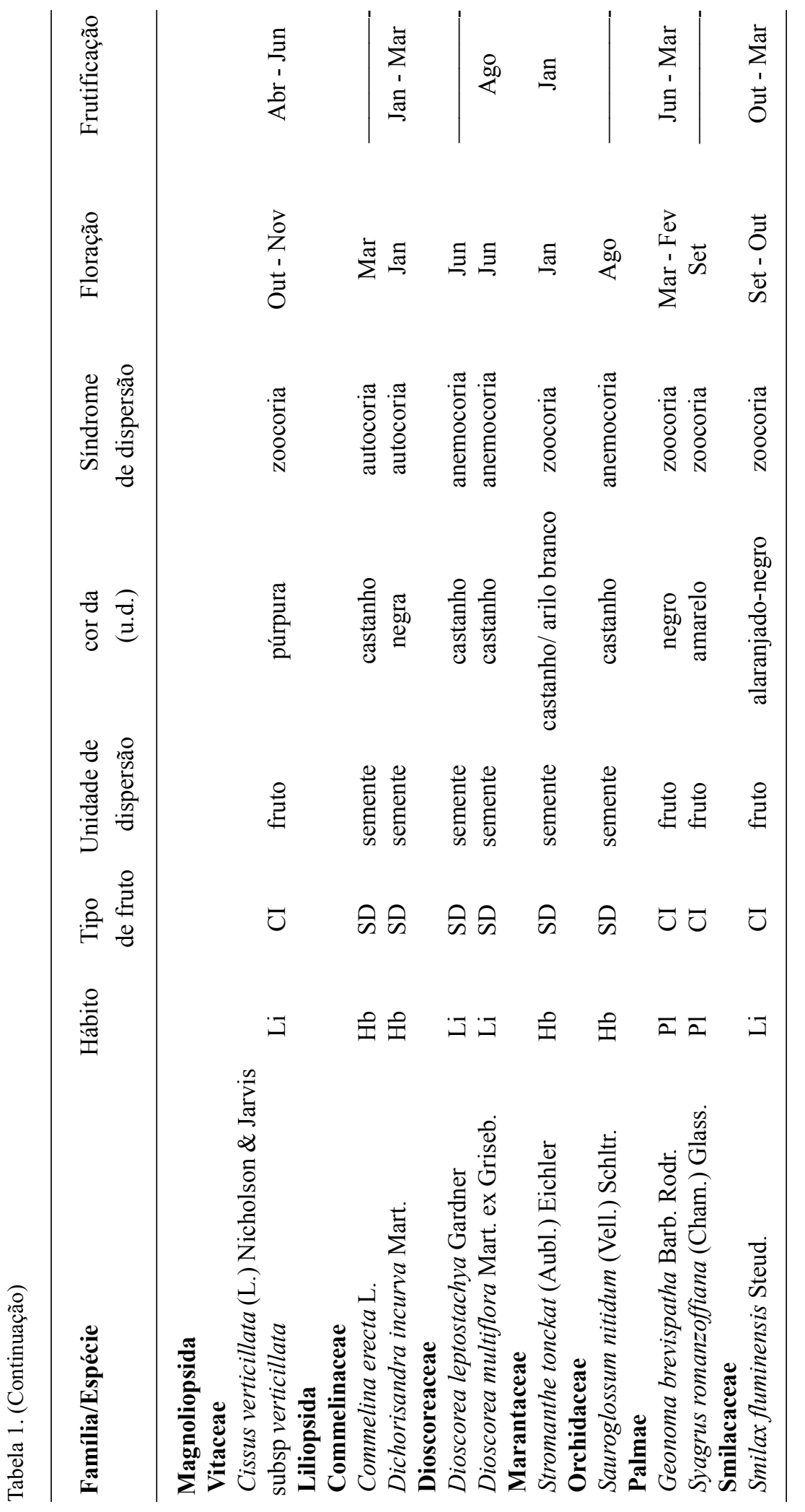



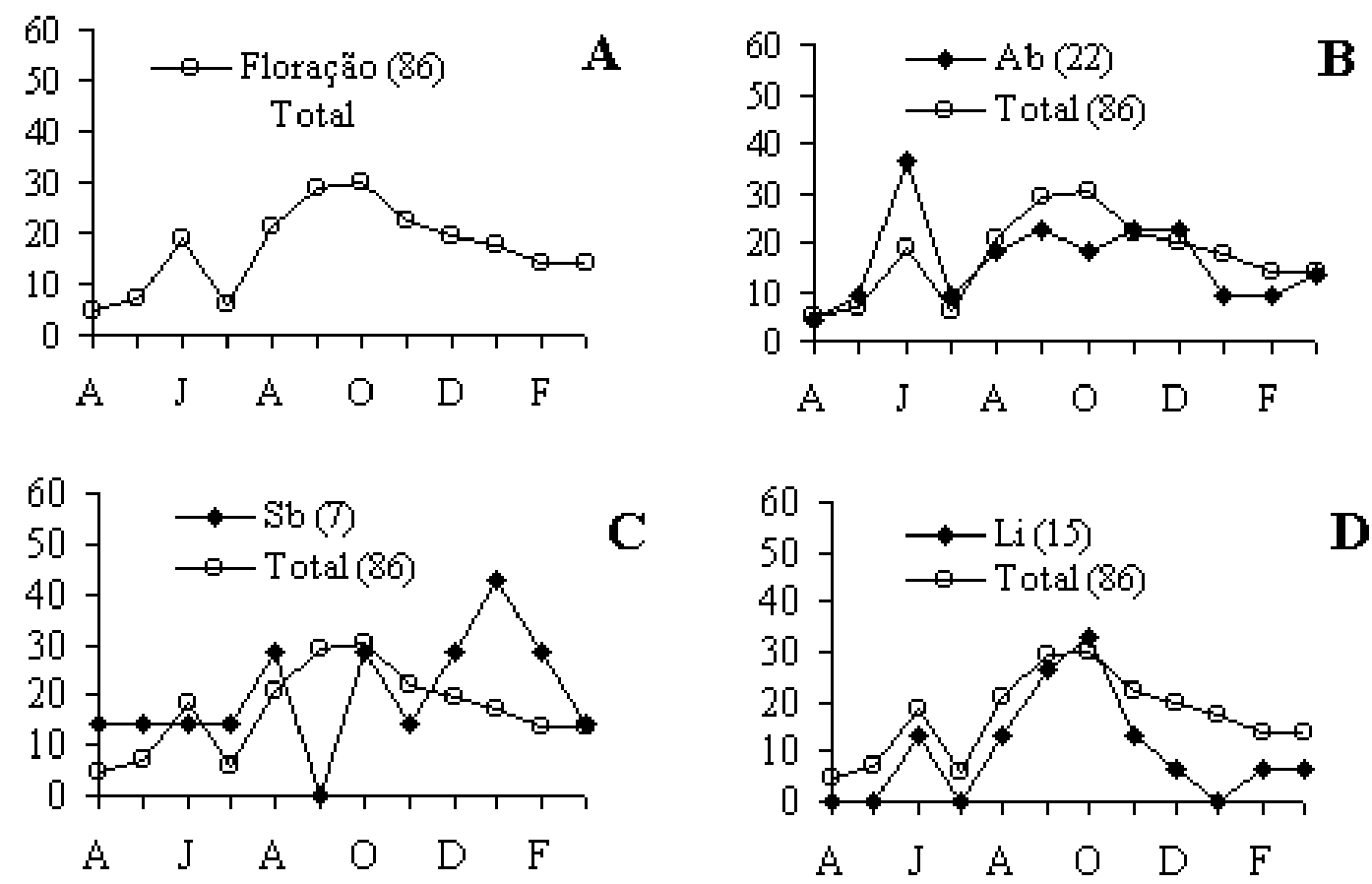

B
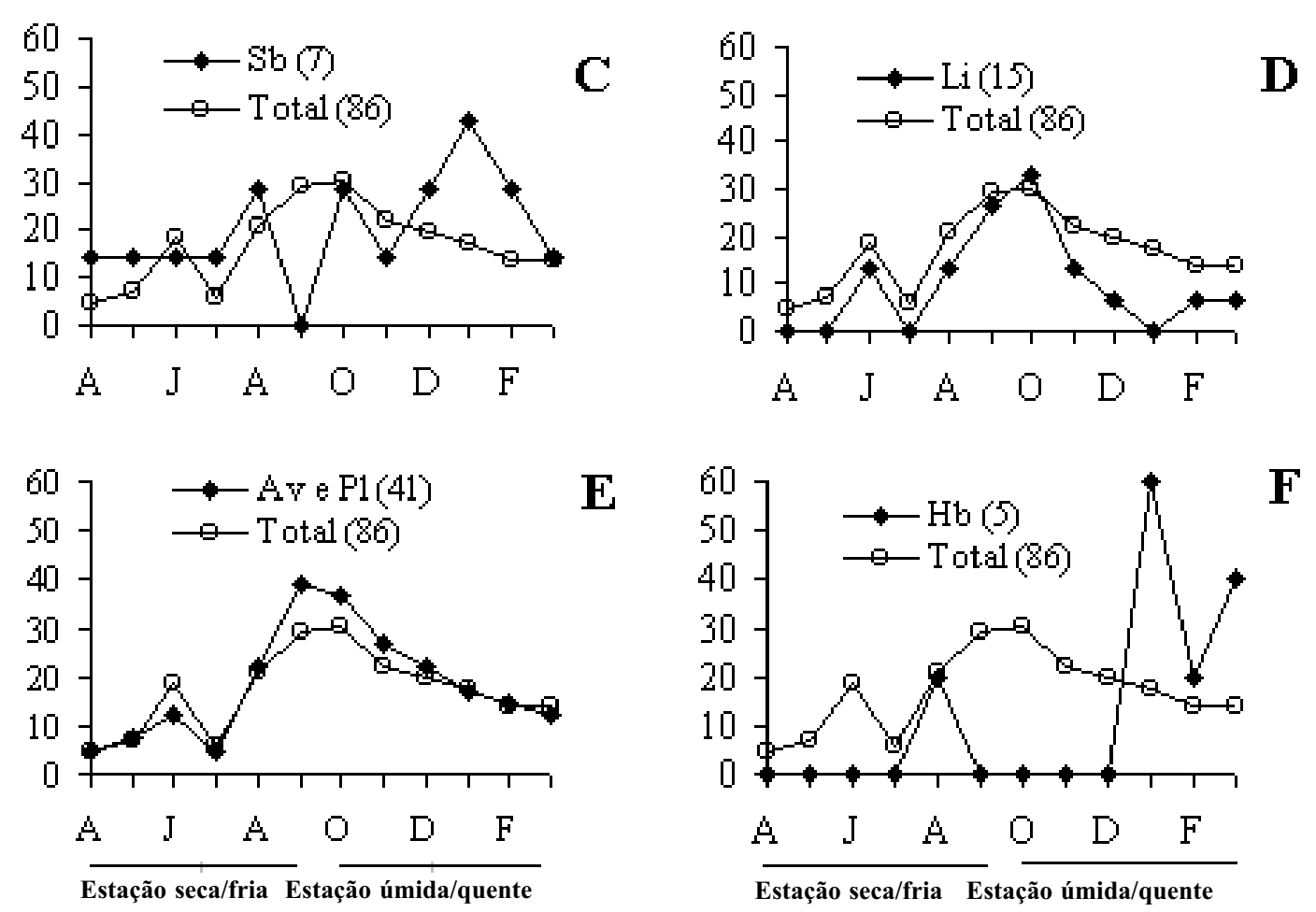

Figura 2 A-F. Picos de floração das espécies da floresta de brejo estudada, durante o período de abril 1994 a março 1995. B-F. Espécies agrupadas de acordo com o seu hábito: B- arbustivas (Ab), C-subarbustivas (Sb), D- lianas (Li), Earborescentes (árvores $(\mathrm{Av})$ e palmeiras $(\mathrm{Pl})$ ) e F- herbáceas $(\mathrm{Hb})$. O número de espécies, de cada gráfico, está indicado entre parênteses.

nesta estratificação, podemos notar que as espécies do estrato arbóreo apresentaram o seu maior pico de floração (agosto-outubro) durante a estação úmida/quente, com o pico das espécies arborescentes antecedendo o das espécies de lianas (Fig. 2 E-D); o estrato herbáceo também apresentou seu maior pico de floração durante a estação úmida/quente (janeiro) (Figs. 2 $\mathrm{C}$ e $2 \mathrm{~F}$ ) com este ocorrendo depois do pico de floração do estrato arbóreo; e as espécies do estrato arbustivo apresentaram o seu maior pico de floração durante a estação seca (junho) (Fig. 2B). Estes dados sugerem que apesar da comunidade apresentar uma sincronia de floração para uma determinada estação do ano, esta, quando analisada em estratos, apresenta uma assincronia de floração entre os três estratos da floresta. 

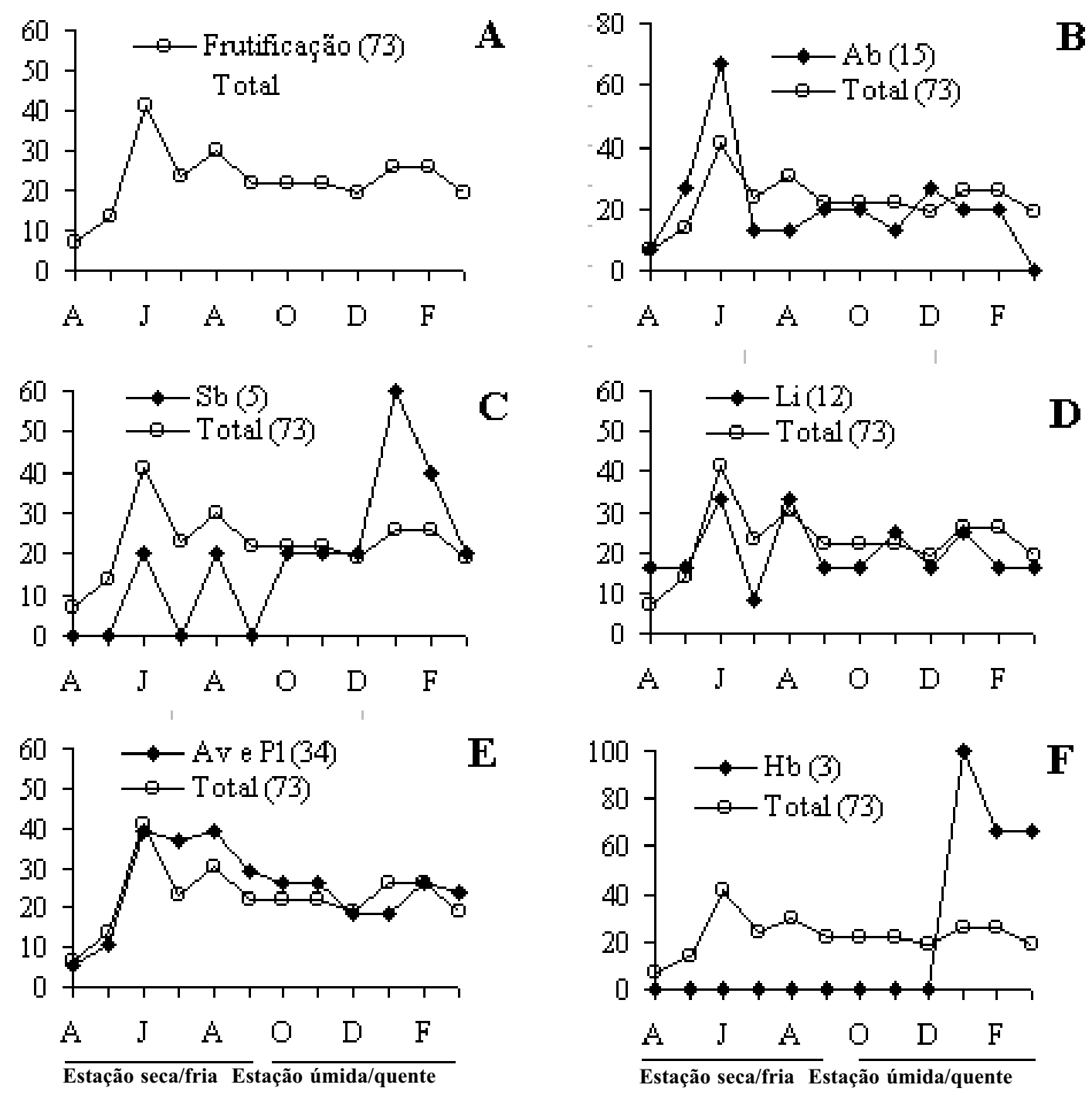

Figura 3 A - Picos de frutificação das espécies da floresta de brejo estudada, durante o período de abril 1994 a março 1995. B-F. Espécies agrupadas de acordo com o seu hábito: B- arbustivas (Ab), C-subarbustivas (Sb), D- lianas (Li), Earborescentes (árvores $(\mathrm{Av})$ e palmeiras $(\mathrm{Pl})$ ) e F- herbáceas $(\mathrm{Hb})$. O número de espécies, de cada gráfico, está indicado entre parênteses.

Frutificação e síndromes de dispersão Para a fenofase de frutificação foram observadas $55 \%$ das espécies ( 73 espécies) durante o período de coleta do material botânico (de abril 1994 a março 1995), sendo que este valor foi usado como unidade amostral na representação dos picos de frutificação das espécies da comunidade (Tab. 1). Na tabela 1 são apresentados para as espécies, dados sobre o hábito, bem como as características dos frutos usadas na classificação destas nas três síndromes de dispersão. A comunidade apresentou espécies frutificando ao longo do ano todo, sendo que os maiores picos ocorreram durante os meses de junho $(41 \%)$, agosto (30\%) e de janeiro a fevereiro (26\%) (Fig. 3 A). Ao se analisar a época de frutificação para as espécies nos diferentes hábitos, observa-se que há variação no pico de 
Tabela 2. Percentual de espécies florescendo em cada estação do ano (estação seca/fria e estação úmida/quente). As espécies foram agrupadas de acordo com o hábito: arborescentes (árvores (Av) e palmeiras (Pl)), arbustivas (Ab), subarbustivas $(\mathrm{Sb})$, lianas $(\mathrm{Li})$ e herbáceas $(\mathrm{Hb})$. O número de espécies está indicado entre parênteses.

\begin{tabular}{lccc}
\hline \multirow{2}{*}{ Hábito } & $\begin{array}{c}\text { Estações seca/fria } \\
\text { Abril a setembro }\end{array}$ & $\begin{array}{c}\text { Estações úmida/quente } \\
\text { Outubro a Março }\end{array}$ & Ambas as estações \\
\cline { 2 - 4 } & Total & Total & Total \\
\hline Av e PI (40) & $40 \%$ & $35 \%$ & $26 \%$ \\
Ab (21) & $38 \%$ & $48 \%$ & $19 \%$ \\
Sb (7) & $29 \%$ & $71 \%$ & 0 \\
Li (13) & $39 \%$ & $46 \%$ & $15 \%$ \\
Hb (5) & $20 \%$ & $80 \%$ & 0 \\
\hline Total (86) & $\mathbf{3 6 \%}$ & $\mathbf{4 5 \%}$ & $\mathbf{1 8 \%}$ \\
\hline
\end{tabular}

frutificação ao longo do ano (Figs. 3 A-F). Pela Tabela 3 podemos observar que cerca de $71 \%$ das espécies frutificam apenas durante uma estação do ano (estação seca/fria ou estação úmida/quente) e que $29 \%$ das espécies apresentam uma frutificação longa durante as duas estações do ano (estações seca/fria e úmida/quente).

Dentro destes $29 \%$ estão representadas espécies de hábito arbustivo (40\% das espécies), arborescente (37\%) e escandente (8\%) (Tab. 3).

Na figura $3 \mathrm{~B}$ podemos observar que as espécies arbustivas apresentaram seu maior pico de frutificação (67\% das espécies) em junho durante a estação seca/fria enquanto que na estação úmida/quente estas apresentaram picos menores variando de 20 a $27 \%$.

Esta tendência em ocorrer uma maior frutificação durante a estação seca/fria, também pode ser observada na tabela 3 , onde cerca de $53 \%$ das espécies arbustivas frutificaram nesta estação e apenas $6,5 \%$ durante a estação úmida/quente. Dentro destes, $53 \%$ das espécies arbustivas, a zoocoria foi à síndrome que apresentou a maior porcentagem $(40 \%$ das espécies), embora ocorram em menores porcentagens espécies anemocóricas e autocóricas, cerca de 6,5\% (Tab. 3). No entanto, dentro das espécies arbustivas que frutificam durante a estação úmida/quente (6,5\% das espécies) ocorrem apenas espécies autocóricas. Para as espécies arbustivas que frutificam ao longo das duas estações ( $40 \%$ das espécies) foi observado que todas são zoocóricas (Tab. 3).

Nas espécies subarbustivas o maior pico de frutificação ( $60 \%$ das espécies) ocorre durante a estação úmida/fria (janeiro), sendo que, $40 \%$ destas espécies são zoocóricas e $20 \%$ são autocóricas (Fig. 3 C, Tab. 3). Já durante a estação seca/fria às espécies subarbustivas apresentam dois picos menores de frutificação ( $20 \%$ das espécies) os quais se referem às espécies autocóricas (40\% das espécies) (Fig. 3, Tab. 3).

As espécies escandentes (lianas) apresentaram 2 picos maiores de frutificação durante estação seca (junho e agosto) e 2 menores durante a estação úmida (novembro e janeiro) (Fig. 3 D). Estas também apresentaram $8 \%$ das espécies frutificando durante as duas estações do ano (Tab. 3).

No entanto as espécies que frutificaram durante a estação úmida e durante as duas estações do ano são todas zoocóricas enquanto que $58 \%$ das espécies da estação seca são anemocóricas (Tab. 3) 


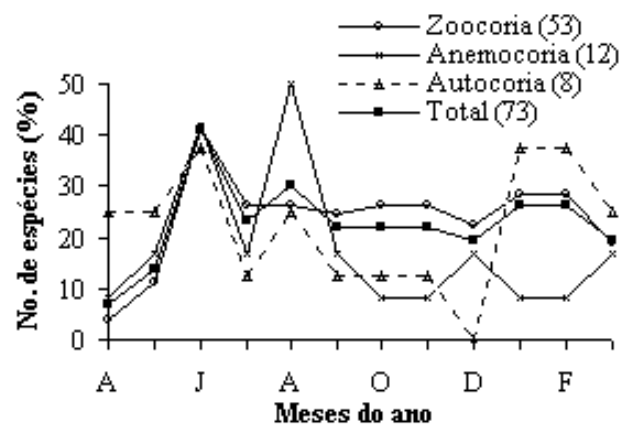

Figura 4. Picos de frutificação das espécies da floresta de brejo estudada, agrupadas de acordo com a síndrome de dispersão (de abril de 1994 a março de 1995). O número de espécies, por síndrome de dispersão, está indicado entre parênteses.

Para as arborescentes observou-se que o número de espécies frutificando durante a estação seca (34\% das espécies) e ao longo das duas estações (37\%) apresentaram proporções semelhantes, enquanto que para as espécies da estação úmida foi encontrada uma porcentagem menor $(29 \%)$ (Tab. 3). Porém o maior pico de frutificação para as arborescentes ocorre de junho a agosto ( 37 a $39,5 \%$ das espécies) durante a estação seca/fria (Fig. 3 E). Em relação à sín- drome de dispersão das espécies arborescentes, a zoocoria ocorreu na maioria das espécies tanto na estação seca/fria ( $31 \%$ das espécies) como na estação úmida/quente (26\%) e ao longo das duas estações do ano (29\%) (Tab. 3).

Diferentemente das espécies nos demais hábitos, as espécies herbáceas frutificam durante uma única estação do ano (estação úmida/quente), apresentando um pico acentuado em janeiro $(100 \%)$, das quais, $67 \%$ são autocóricas e $33 \%$ são zoocóricas (Fig. 3 F, Tab. 3).

Com relação às síndromes de dispersão da comunidade como um todo (Fig. 4) foi observado que as espécies zoocóricas apresentaram uma frutificação contínua ao longo do ano, um padrão fortemente influenciado pelas espécies arborescentes e arbustivas, que apresentaram a zoocoria como o modo de dispersão mais freqüente $(75 \%$ e $57 \%$ das espécies, respectivamente) (Tab. 4). A anemocoria apresentou seu maior pico de frutificação (50\% das espécies) durante a estação seca e fria (agosto) (Fig. 4), sendo que este é influenciado pelo comportamento das espécies escandentes (lianas) (Fig. 3D). Para as espécies autocóricas foram observados três picos de frutificação, dois durante a estação seca e fria (junho e agosto) e o terceiro

Tabela 3. Percentual de espécies frutificando em cada estação do ano (estação seca/fria e estação úmida/quente). As espécies foram agrupadas de acordo com o hábito: arborescentes (árvores $(\mathrm{Av})$ e palmeiras $(\mathrm{Pl})$ ), arbustivas $(\mathrm{Ab})$, subarbustivas $(\mathrm{Sb})$, lianas ( $\mathrm{Li})$ e herbáceas $(\mathrm{Hb})$; e o modo de dispersão: zoocoria (Zoo), anemocoria (Anemo) e autocoria (Auto). O número de espécies está indicado entre parênteses.

\begin{tabular}{|c|c|c|c|c|c|c|c|c|c|c|c|c|}
\hline & \multicolumn{4}{|c|}{ Estação seca/fria } & \multicolumn{4}{|c|}{ Estação úmida/quente } & \multicolumn{4}{|c|}{ Ambas } \\
\hline & $\begin{array}{l}\text { Zoo } \\
(\%)\end{array}$ & $\begin{array}{c}\text { Anemo } \\
(\%)\end{array}$ & $\begin{array}{l}\text { Auto } \\
(\%)\end{array}$ & $\begin{array}{c}\text { Total } \\
(\%)\end{array}$ & $\begin{array}{l}\text { Zoo } \\
(\%)\end{array}$ & $\begin{array}{c}\text { Anemo } \\
(\%)\end{array}$ & $\begin{array}{l}\text { Auto } \\
(\%)\end{array}$ & $\begin{array}{c}\text { Total } \\
(\%)\end{array}$ & $\begin{array}{l}\text { Zoo } \\
(\%)\end{array}$ & $\begin{array}{r}\text { Anemo } \\
(\%)\end{array}$ & $\begin{array}{l}\text { Auto } \\
(\%)\end{array}$ & $\begin{array}{r}\text { Total } \\
(\%)\end{array}$ \\
\hline Av e Pl (38) & 31 & 3 & 0 & 34 & 26 & 3 & 0 & 29 & 29 & 5 & 3 & 37 \\
\hline Ab (15) & 40 & 6.5 & 6.5 & 53 & 0 & 0 & 6.5 & 6.5 & 40 & 0 & 0 & 40 \\
\hline Sb (5) & 0 & 0 & 40 & 40 & 40 & 0 & 20 & 60 & 0 & 0 & 0 & $\mathbf{0}$ \\
\hline Li (12) & 8 & 58 & 0 & 66 & 25 & 0 & 0 & 25 & 8 & 0 & 0 & 8 \\
\hline Hb (3) & 0 & 0 & 0 & $\mathbf{0}$ & 33 & 0 & 67 & 100 & 0 & 0 & 0 & $\mathbf{0}$ \\
\hline Total (65) & 26 & 12 & 4 & 42 & 22 & 1 & 6 & 29 & 25 & 3 & 1 & 29 \\
\hline
\end{tabular}


Tabela 4. Síndromes de dispersão das espécies da comunidade de floresta de brejo estudada e seus respectivos números e porcentagens, de acordo com o hábito: arborescentes (árvores (Av) e palmeiras (Pl)), arbustivas (Ab), subarbustivas (Sb), lianas (Li) e herbáceas $(\mathrm{Hb})$.

\begin{tabular}{lcccccc}
\hline & $\begin{array}{c}\text { Arborescentes } \\
\text { (Av e Pl) }\end{array}$ & $\begin{array}{c}\text { Arbustivas } \\
(\mathbf{A b})\end{array}$ & $\begin{array}{c}\text { Subarbustivas } \\
\mathbf{( S b )}\end{array}$ & $\begin{array}{c}\text { Lianas } \\
(\mathbf{L i})\end{array}$ & $\begin{array}{c}\text { Herbáceas } \\
(\mathbf{H b})\end{array}$ & Total \\
\hline $\begin{array}{l}\text { Síndromes de } \\
\text { dispersão }\end{array}$ & №/(\%) & №/(\%) & №/(\%) & №/(\%) & №/(\%) & №/(\%) \\
$\begin{array}{l}\text { Zoocoria } \\
\text { Anemocoria }\end{array}$ & $49(75 \%)$ & $16(57 \%)$ & $4(50 \%)$ & $7(26 \%)$ & $1(17 \%)$ & $77(57 \%)$ \\
Autocoria & $7(12 \%)$ & $8(29 \%)$ & $1(12,5 \%)$ & $17(63 \%)$ & $2(33 \%)$ & $36(27 \%)$ \\
\hline Total & $\mathbf{6 5 ( 1 0 0 \% )}$ & $\mathbf{2 8 ( 1 0 0 \% )}$ & $\mathbf{8 ( 1 0 0 \% )}$ & $\mathbf{2 7 ( 1 0 0 \% )}$ & $\mathbf{6 ( 1 0 0 \% )}$ & $\mathbf{1 3 4}(\mathbf{1 0 0 \% )}$ \\
\hline
\end{tabular}

durante a estação úmida e quente (de janeiro a fevereiro) (Fig. 4). Estes picos da estação seca/ fria refletem o comportamento das espécies subarbustivas (Fig. $3 \mathrm{C}$ ), enquanto que o pico da estação úmida/quente reflete o das espécies herbáceas (Fig. $3 \mathrm{~F}$ ). Para estes dois hábitos são encontradas as maiores freqüências de espécies autocóricas (Tabs. 3 e 4).

\section{Discussão}

A comunidade estudada apresentou uma sincronia de floração e de frutificação direcionada para uma determinada estação do ano, com a floração apresentando seu maior pico durante a estação úmida/quente e a frutificação durante a estação seca/fria. Este padrão sugere uma sazonalidade na época de ocorrência das fenofases de floração e de frutificação, a qual estaria associada à variação climática durante as duas estações do ano. Tal padrão é citado na literatura como característico das florestas tropicais (Frankie et al. 1974, Matthes 1980, Morellato et al. 1989, Morellato 1991).

As espécies arborescentes, arbustivas, subarbustivas, e de lianas apresentaram também um pico de floração e de frutificação em comum, durante a estação seca (junho). Esta sincronia de floração e de frutificação de várias espécies em diferentes hábitos, não é observa- da para as espécies das florestas semidecíduas (Matthes 1980, Morellato et al. 1989, Morellato 1991). No entanto, este padrão é citado como comum em florestas úmidas dos trópicos (Frankie et al. 1974, Opler, et al. 1980). Apesar dos poucos dados referentes às florestas úmidas, estas evidências sugerem que nestas florestas podem ocorrer alguns padrões fenológicos característicos durante a estação seca, os quais as diferenciariam das florestas secas.

Vários autores relacionam este pico de floração durante a estação seca, das florestas úmidas, com a disponibilidade de água do solo, com a sazonalidade das chuvas, variação na temperatura, com picos de irradiância, e com a baixa herbivoria (Wright 1996).

Reich \& Borchert (1984) observaram que, em locais úmidos, as árvores experimentam pouco ou nenhum "stress" hídrico, e estas se mantêm sempre verdes ou rapidamente trocam suas folhas durante a estação seca.

Para a floresta de brejo estudada foi observado que mesmo durante uma seca prolongada (ausência de precipitação de agosto a setembro de 1994) esta permaneceu com o solo encharcado e manteve a sua aparência perenifólia (Toniato et al., 1998). Esta evidência sugere que a disponibilidade de água no solo é um fator importante, e que talvez esteja influenciando esta sincronia de floração e de frutificação durante 
o mês de junho. Smythe (1970) sugere que, embora os fatores físicos do ambiente possam ser os mais importantes na determinação da época de frutificação, a competição por dispersores pode agir como uma pressão seletiva adicional em que o modo de alimentação dos dispersores pode influenciar a época de amadurecimentos dos frutos, mostrando uma tendência sazonal para as espécies com frutos de sementes grandes e uma diversificação ao longo do ano para as com frutos de sementes pequenas.

O mesmo autor também observou, para a floresta tropical úmida no Panamá, que os maiores picos de frutificação ocorrem durante os meses de maio a julho e que durante estes meses eram amadurecidos os frutos com sementes grandes.

$\mathrm{Na}$ floresta de brejo estudada, as espécies que contribuem para o pico de frutificação durante o mês de junho são na maioria arborescentes e zoocóricas, podendo apresentar como unidades de dispersão frutos pequenos carnosos, indeiscentes com uma ou muitas sementes, como por exemplo: Dendropanax cuneatum, Eugenia florida, Ficus insipida, Geonoma brevispatha, Miconia ligustroides, Ocotea diospyrifolia e Prunus myrtifolia; sementes pequenas e ariladas, como: Clusia criuva, Guarea macrophylla e Talauma ova$\mathrm{ta}$; ou ainda frutos grandes carnosos, indeiscentes como Calophyllum brasiliense e Inga marginata.

Isto indica que apesar da sincronia de frutificação entre a floresta de brejo estudada e a floresta úmida do Panamá durante o mês de junho, estas diferem quanto ao tipo de fruto que está predominando nesta época e, como sugerido por Smythe (1970), estas podem estar sofrendo diferentes influencias dependendo do modo de alimentação dos dispersores.

No entanto, tais tendências necessitam de uma verificação mais detalhada a fim de se verificar como o comportamento dos dispersores estaria direcionado à época de frutifi- cação das espécies da floresta de brejo estudada. As espécies arborescentes zoocóricas apresentaram picos de frutificação durante as duas estações do ano (estação seca/fria e estação úmida/quente), sendo que este mesmo comportamento foi observado por Morellato et al. (1989) para as espécies arbóreas da Reserva Florestal de Santa Genebra.

Morellato et al. (1989) sugerem ainda que entre as espécies que frutificaram na estação seca, a maioria possui síndrome de dispersão anemocórica. Neste trabalho não foi encontrada a mesma relação, talvez devido à baixa porcentagem de espécies anemocóricas entre as espécies arborescentes. Para as espécies arborescentes também foi observado que a zoocoria foi à síndrome de dispersão mais freqüente, e que a anemocoria e a autocoria são pouco freqüentes e apresentam as mesmas porcentagens.

Esta alta porcentagem de espécies zoocóricas encontrada na floresta de brejo, também foi observada para outras florestas na região de Campinas (Matthes 1980, Morellato 1991). Entretanto, nestas florestas a porcentagem de espécies arborescentes anemocóricas foi maior que a apresentada para a floresta de brejo estudada.

As espécies arbustivas apresentaram um maior pico de floração e de frutificação durante a estação seca, e este se deve às espécies zoocóricas. Tal padrão sugere que, apesar do baixo índice pluviométrico desta estação, estas espécies não estariam sendo afetadas na sua produção de frutos e, como já discutido anteriormente, este comportamento pode estar sendo influenciado pela disponibilidade de água no solo da floresta estudada.

As espécies do estrato herbáceo (subarbustivas e herbáceas) apresentaram os seus picos de floração e de frutificação ocorrendo durante a mesma estação do ano, isto é, as espécies que floresceram na estação seca/fria também frutificaram durante esta estação. Isto sugere que as espécies subarbustivas e herbá- 
ceas completam todo o seu ciclo reprodutivo durante uma única estação do ano. Wright (1996) sugere que para as espécies herbáceas do subosque, o déficit hídrico durante a estação seca, é máximo, devido estas apresentarem raízes superficiais. Este déficit hídrico durante a estação seca não ocorre na floresta de brejo estudada, e isso talvez explique porque algumas espécies do estrato herbáceo conseguem completar todo o seu ciclo reprodutivo durante esta estação.

Os maiores picos de frutificação das espécies de lianas da floresta de brejo estudada ocorreram durante a estação seca. Quando relacionamos estes picos de frutificação com as síndromes de dispersão, podemos observar que as espécies anemocóricas apresentam picos de frutificação na mesma época. Isto sugere que estes picos estão sendo influenciados diretamente pelas espécies de lianas anemocóricas. Outro indício desta relação é a alta porcentagem de espécies anemocóricas encontrada entre as espécies de lianas.

Esta alta porcentagem de espécies anemocóricas entre as lianas é dada principalmente pela família Asteraceae. Esta relação também foi observada por Kim (1996) para as espécies de lianas da mata atlântica. Para as espécies de lianas da floresta semidecídua da Reserva Municipal de Santa Genebra também foi observado um pico durante a estação seca (Morellato \& Leitão Filho, 1996).

As espécies de lianas da floresta de brejo estudada apresentam ainda um pequeno pico durante a estação úmida o qual está relacionado com a dispersão de frutos zoocóricos. Tal relação também foi observada para espécies de lianas da floresta atlântica (Kim 1996) e para as da floresta mesófila semidecídua (Morellato \& Leitão Filho, 1996). Em relação à floração das espécies de lianas, foi observado que a época com maior número de espécies em flor antecede a época de maior produção de frutos, e que estas espécies são zoocóricas e autocóricas. Isto sugere que as espécies de lianas anemocóricas florescem logo após as primeiras chuvas de setembro e só vão frutificar durante a estação seca, onde fatores como ventos fortes, e ausência de chuvas, auxiliam a dispersão dos diásporos.

A frutificação contínua ao longo do ano, apresentada pelas espécies da comunidade, reflete o comportamento das espécies zoocóricas, as quais foram mais freqüentes nas espécies arborescentes.

Para as espécies anemocórias foram observados picos acentuados durante a estação seca, os quais são influenciados pelo comportamento das espécies de lianas. Nas florestas secas os frutos carnosos se concentram durante a estação úmida e os anemocóricos durante a estação seca (Frankie et al. 1974, Mantovani \& Martins 1988, Bullock \& Solís-Magallanes 1990, Oliveira \& Moreira 1992, Machado et al. 1997).

Mantovani \& Martins (1988) verificaram que a deiscência e a dispersão das espécies anemocóricas é facilitada pela desidratação do pericarpo e pela perda de folhas durante a época seca. Estes fatores, juntamente com ventos fortes e ausência de chuvas durante esta época, podem explicar a tendência, para estes períodos, da frutificação das espécies anemocóricas da floresta de brejo estudada.

Por outro lado, as espécies com frutos carnosos (zoocóricos) apresentam forte influência dos agentes dispersores, dificultando assim a associação entre a época de ocorrência e os fatores bióticos relacionados.

As florestas de brejos necessitam ser preservadas e melhor estudadas quanto à sua dinâmica, por apresentarem características próprias quanto ao encharcamento do solo, a composição florística e ao padrão fenológico, e por estarem associadas às nascentes de rios que são de extrema importância para a manutenção das bacias hidrográficas.

Torna-se importante ressaltar ainda a necessidade de estudos fenológicos detalhados para as florestas de brejo, a fim de se confir- 
mar os padrões apresentados neste trabalho, bem como para um maior conhecimento das relações entre os agentes dispersores e polinizadores desta comunidade florestal.

\section{Agradecimentos}

Os autores agradecem à pesquisadora Dra. Roseli Torres pela leitura crítica do manuscrito e valiosas sugestões, à EMBRAPA pela foto aérea da área de estudo, e à CAPES pela bolsa de mestrado concedida à primeira autora.

\section{Referências bibliográficas}

Brummitt, R. K. \& Powell, C. E. 1992. Authors of plant names. Whiststabable Litho ltds, Great Britain.

Bullock, S. H., \& Solís-Magallanes, J. A. 1990. Phenology of Canopy trees of a tropical deciduous forest in México. Biotropica 22(1): 22-35.

Cronquist, A. 1981. An integrated system of classification of flowering plants. Columbia University Press. New York.

Frankie, G. F., Baker, H. G. \& Opler, P. A. 1974. Comparative phenological studies of trees in tropical wet and dry forests in the lowlands of Costa Rica. Journal of Ecology. 62(3): 881-913.

Font Quer, P. 1979. Dicionário de botânica. Editorial Labor S.A., Barcelona.

Ivanauskas, N. M., Rodrigues, R. R., \& Nave A. G. 1997. Aspectos ecológicos de um trecho de floresta de brejo em ltatinga-SP: florística, fitossociologia e seletividade de espécies. Revista Brasileira de Botânica 20:139-153.

Kim, A. C. 1996. Lianas da Mata Atlântica do Estado de São Paulo. Dissertação de Mestrado, Campinas, UNICAMP.

Machado, I. C. S., Barros, L. M. \& Sampaio, E. V. S. B. 1997. Phenology of caatinga species at Serra Talhada, PE, northeastern Brazil. Biotropica 29(1): 57-68.

Mantovani, W. \& Martins, F. R. 1988. Variações fenológicas das espécies do cerrado da Reserva Biológica de Moji Guaçu, Estado de São Paulo. Revista Brasileira de Botânica 11: 101-112.

Matthes, L. A. F. 1980. Composição florística, estrutura e fenologia de uma floresta residual do planalto paulista: Bosque dos Jequitibás (Campinas, SP.). Dissertação de Mestrado, Campinas, UNICAMP.
Matthes, L. A. F. 1992. Dinâmica de sucessão secundária em mata, após a ocorrência de fogo - Santa Genebra - Campinas, São Paulo. Tese de Doutorado, Campinas, UNICAMP.

Mello, M. H. A., Júnior Pedro, M. J., Ortolani, A. A. \& Alfonsi, R. R. 1994. Chuva e temperatura: cem anos de observações em Campinas. Boletim Técnico do Instituto Agronômico de Estado de São Paulo 154: 1-48.

Morellato, L. P. C., Rodrigues, R. R., Leitão Filho, H. F., \& Joly, C. A. 1989. Estudo comparativo da fenologia de espécies arbóreas de floresta de altitude e floresta mesófila semidecídua na Serra do Japi, Jundiaí, São Paulo. Revista Brasileira de Botânica 12: 85-98.

Morellato, L. P. C. 1991. Estudos da fenologia de árvores, arbustos e lianas de uma floresta semidecídua no sudeste do Brasil. Tese de Doutorado, Campinas, UNICAMP.

Morellato, L. P. C. \& Leitão Filho, H. F. 1996. Reproductive phenology of climbers in a southeastern brazilian forest. Biotropica 28(2): 180191.

Oliveira, J. B., Menk, J. R. F. \& Rotta, C. L. 1979. Levantamento pedológico semidetalhado dos solos do estado de São Paulo - quadrícula de Campinas. IBGE, Rio de Janeiro.

Oliveira, P. E. A. M. \& Moreira, A. G. 1992. Anemocoria em espécies de cerrado e mata de galeria de Brasília, DF. Revista Brasileira de Botânica 15(2): 163-174.

Opler, P. A., Frankie, G. W. \& Baker, H. G. 1980. Comparative phenological studies of treelet and shrub species in tropical wet and dry forests in the lowlands of Costa Rica. Revista Brasileira de Botânica 68: 167-188.

Pijl, L. van der 1982. Principles of Dispersal in Higher Plants. $2^{\text {a }}$ ed., Springer-Verlag, Berlim.

Rathcke, B. \& Lacey, E. P. 1985. Phenological patterns of terrestrial plants. Annual Review of Ecology and Systematics 16: 179-214.

Reich, P. \& Borchert, R. 1984. Water stress and tree phenology in a tropical dry forest in the lowlands of Costa Rica. Journal of Ecology 72: 61-74.

Rizzini, C. T. \& Rizzini, C. M. 1983. Dicionário botânico clássico latino-português abonado. IBDFJardim botânico, Rio de Janeiro.

Smythe, N. 1970. Relationships between fruiting seasons and seasons and seed dispersal methods in a neotropical forest. The American Naturalist 104(935): 25-35. 
Spina, A. P., 1997. Composição florística de uma floresta de brejo na região de Campinas, e algumas considerações sobre os sistemas sexuais, a fenologia de floração e de frutificação e as síndromes de dispersão das espécies da comunidade. Dissertação de Mestrado, Campinas, UNICAMP.

Toniato, M. T. Z., Leitão Filho, H. F., \& Rodrigues, R. R. 1998. Fitossociologia de um remanescente de floresta higrófila (mata de brejo) em Campinas, SP. Revista Brasileira de Botânica 21(2): 197-210.

Torres, R. B.; Matthes, L. A. F. \& Rodrigues, R. R. 1994. Florística e estrutura do componente arbóreo de mata de brejo em Campinas, SP. Revista Brasileira de Botânica 17(2): 189-194.

Wright, S. J. 1996: Phenological responses to seasonality in tropical forest plants Pp. 440-460. In: S. S. Mulkey, R. L. Chazdon \& A. P. Smith (ed.), Tropical forest plant ecophysiology. Chapman \& Hall, New York. 